\title{
A RARE CASE OF SYNOVIAL CHONDROMATOSIS OF KNEE WITH MULTIPLE INTRA-ARTICULAR LOOSE BODIES MANAGED BY ARTHROSCOPIC ASSISTED LOOSE BODY REMOVAL AND SYNOVECTOMY
}

\author{
P. V. Pugalenthi', T. Saravanamuthu², S. Abdul Ajees ${ }^{3}$
}

${ }^{1}$ HOD, Department of Orthopaedics and Traumatology, Madurai Medical College, Madurai.

${ }^{2}$ Assistant Professor, Department of Orthopaedics and Traumatology, Madurai Medical College, Madurai.

3Postgraduate Student, Department of Orthopaedics and Traumatology, Madurai Medical College, Madurai.

\begin{abstract}
\section{BACKGROUND}

Synovial chondromatosis is a type of non-cancerous tumour arising from the intimal layer of synovial membrane of a joint. The knee is most commonly affected followed by hip, hand, wrist. Elbow and shoulder are least common; however, it can affect any joint. The tumours begin as small nodules of cartilage. The cartilage foci become pedunculated and may be sequestrated into the synovial cavity to form multiple loose bodies, often in pearly clumps resembling sago "snowstorm knee". Some tumours may be no larger than a grain of rice. Synovial chondromatosis most commonly occurs in adults ages 20 to 50 with male predominance, mechanical symptoms in joint due to loose bodies, limited range of motion. Plain radiograph shows small calcified intra-articular nodules, advanced disease shows periarticular bone erosion and extension into soft tissues. Treatment modalities are observation if asymptomatic, arthroscopic or open synovectomy. Recurrence most common with arthroscopic synovectomy. In our study, we have done arthroscopic loose body removal and synovectomy.
\end{abstract}

\section{CASE REPORT}

A 65-year-old male with complaints of pain and restricted range of movement of right knee for past 2 years. X-ray showed multiple intra-articular loose bodies of varying sizes, and was diagnosed as synovial chondromatosis with multiple intra-articular loose bodies in right knee.

\section{CONCLUSION}

Even though the mentioned procedure requires surgical expertise, arthroscopic assisted loose body removal is an accepted novel procedure for synovial chondromatosis with multiple loose bodies.

\section{KEYWORDS}

Synovial Chondromatosis, Arthroscopy, Loose Bodies, Synovectomy.

HOW TO CITE THIS ARTICLE: Pugalenthi PV, Saravanamuthu T, Ajees SA. A Rare case of Synovial chondromatosis of knee with multiple intra-articular loose bodies managed by arthroscopic assisted loose body removal and synovectomy. J. Evolution Med. Dent. Sci. 2017;6(35):2932-2935, DOI: 10.14260/Jemds/2017/631

\section{BACKGROUND}

Synovial chondromatosis(1) also known as synovial osteochondromatosis is a type of non-cancerous tumour arising from the intimal layer of synovial membrane of a joint.(2) The knee is most commonly affected followed by hip,(3) hand, wrist. Elbow and shoulder are least common; however, it can affect any joint. The tumours begin as small nodules of cartilage. The cartilage foci become pedunculated and may be sequestrated into the synovial cavity to form multiple loose bodies, often in pearly clumps resembling sago "snowstorm knee".

Some tumours may be no larger than a grain of rice. Synovial chondromatosis most commonly occurs in adults, 20 to 50 years, with male predominance.

Financial or Other, Competing Interest: None.

Submission 24-01-2017, Peer Review 17-04-2017,

Acceptance 24-04-2017, Published 01-05-2017.

Corresponding Author:

Dr. S. Abdul Ajees,

\#1, T. Oorani South Street,

Devakottai, Sivagangai-630302,

Tamilnadu.

E-mail:dr.ajeesdvk@gmail.com

DOI: $10.14260 /$ jemds $/ 2017 / 631$

\section{(c) $(1)(5)$}

\begin{abstract}
Aetiology
Articular synovial chondromatosis is a benign, slowly progressive condition with a strong tendency to eventual resolution. There are no cartilage cells in normal synovial membrane. The foci of cartilage in chondromatosis are formed by metaplasia of the synovial cells into chondrocyte. The stimulus to this metaplasia is unknown. It has been suggested that the cause lies in overactivity of embryonic cell rest at the synovio-cartilage junction, but the cartilage cells are normally found in the transition zone between synovial membrane and articular cartilage, and belong to the latter tissue.(4)

An alternate explanation for the appearance of masses of cartilage and bone in the synovial lining of joints lies in the well-known phagocytic ability of synovial membrane. Detritus of cartilage and bone from the degenerated articular surfaces of an osteoarthritic joint is absorbed by synovial membrane.

Symptoms and signs of articular synovial chondromatosis are nonspecific. In knee joint, there may be limited range of movement, swelling, crepitus and occasionally loose bodies can be felt. In other joints, accurate clinical diagnosis is not always possible.
\end{abstract}




\section{Imaging and Diagnosis}

X-ray imaging shows fine stippled calcification. Intra-articular loose bodies are seen in $>70 \%$, in primary synovial chondromatosis the loose bodies are typically numerous, small, round, and uniform in size. In secondary cases, loose bodies are small and variable in size. Periarticular erosive changes may be seen, particularly in joint with tight capsule (e.g., hip, wrist). In late stage of the disease, degenerative changes may be seen (joint space narrowing, osteophyte formation, periarticular sclerosis). CT and MRI will detect radiolucent loose bodies that are not visible on $\mathrm{x}$-ray. Radiographic changes when present, confirm the diagnosis, more often they are absent. It must be stressed that numerous loose bodies seen on a radiograph of an affected joint do not necessarily imply a diagnosis of chondromatosis. When joint is extensively involved the diagnosis is obvious at arthrotomy. Areas of loose bodies present as soon as the joint is opened. Areas of synovial membrane which appear macroscopically normal can show the typical microscopic changes. Confirmation of diagnosis is obtained by histological examination. Numerous rounded masses of cartilage, often with bony centres, are seen lying immediately under the surface of the synovial membrane. These foci may be sessile, or pedunculated. Transition zone of metaplasia surrounds the focus.

\section{Classification}

Milgram classified synovial chondromatosis(5) into three stages.

\section{Early}

Active synovial disease, no loose bodies.

\section{Transitional}

Active synovial disease and loose bodies.

\section{Late}

Loose bodies but no synovial disease.

\section{Management}

In present series simple removal of loose bodies(6) has been adequate. When pedunculated chondromatous masses interfere with joint function they should be removed. Complete synovectomy is impractical in the knee, and in hip it entails dislocation. More skills in the use of the arthroscopy is required for the removal of loose bodies than for simple diagnostic arthroscopy. The surgeons must be familiar with several arthroscopic insertions, including the anteromedial, the lateral suprapatellar and posteromedial as well as the standard anterolateral approach.

\section{CASE REPORT}

A 65-year-old male with complaints of pain in right knee, progressive for past 2 years, restricted range of movements and sensation of swelling moving in and around knee joint for past 1 year.

\section{Inspection}

Right knee in flexion of about $20^{\circ}$, diffuse swelling present in Right knee with obliteration of supra \& infrapatellar fossa, popliteal fossa free, skin over knee normal, calf and thigh muscle wasting present, no limb length discrepancy.

\section{Palpation}

No warmth. Joint line tenderness present, synovial thickening present, multiple mobile loose bodies palpated on rolling the synovial membrane over femoral condyle mainly on lateral suprapatellar fossa, no regional lymph nodes palpable.

\section{Movements}

Flexion of Right knee about $0-90^{\circ}$, further flexion restricted with mechanical block and painful. No limb length discrepancy. Test for ligament instability negative.

\section{Investigations}

Routine blood investigations taken, ESR found to be 50 $\mathrm{mm} / \mathrm{hr}$. Plain antero-posterior (fig:1) and lateral (fig;2) radiograph of x-ray Right knee shows multiple radio-opaque loose bodies of varying sizes present over supero-lateral aspect and intra-articular loose bodies of varying sizes.

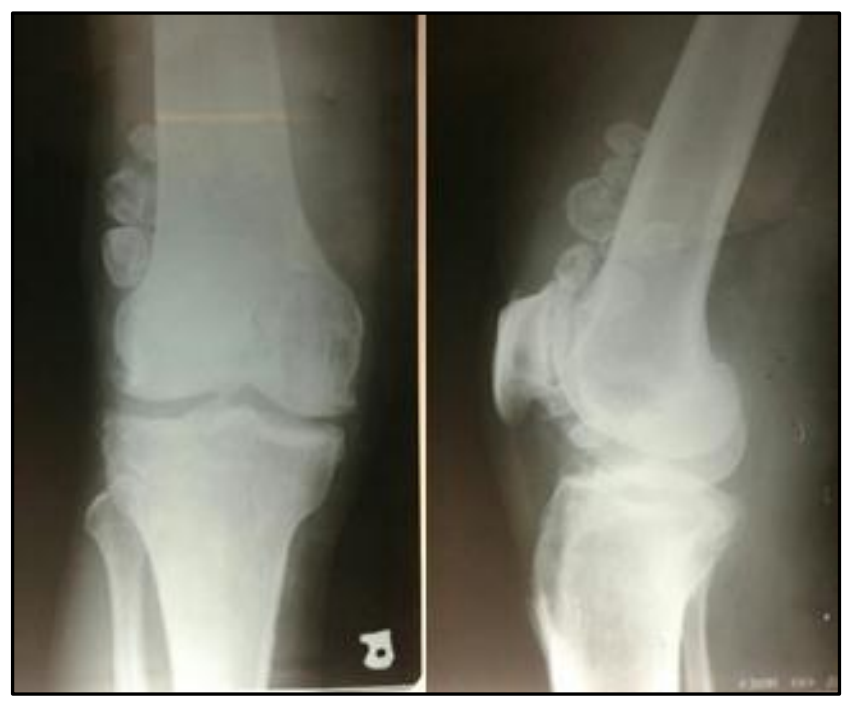

Figure 1

Figure 2

\section{Surgical Technique}

Under sterile aseptic precaution on spinal anaesthesia, patient on supine position. Surgical parts painted and draped. Right knee kept in $45^{\circ}$ flexion. Anterolateral diagnostic portal (fig: 1) was made. Through arthroscopic (7) march was done. Multiple loose bodies present over superolateral pouch and intercondylar region (Fig: 2, 3, 4). ACL, PCL and meniscus found to be intact. All loose bodies are identified through arthroscopically, (8) then $1 \mathrm{~cm}$ nick was made just opposite to anterolateral portal (Fig: 5) (on anteromedial aspect). Through the nick using Kocher's forceps (Fig: 6) all loose bodies were removed with the help of arthroscopic shaver synovectomy done. Intra-operatively checked for flexion and extension of knee, found to satisfactory.

Intra-operative findings: Numerous rounded masses of cartilage, often with bony centres, are seen immediately under the surface of synovial membrane. 


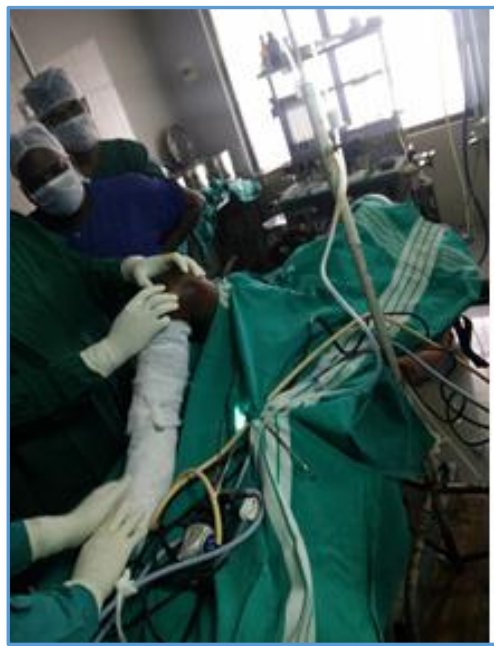

Figure 1

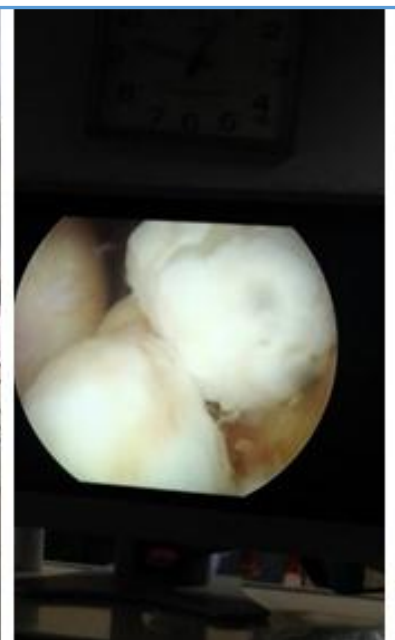

Figure 2

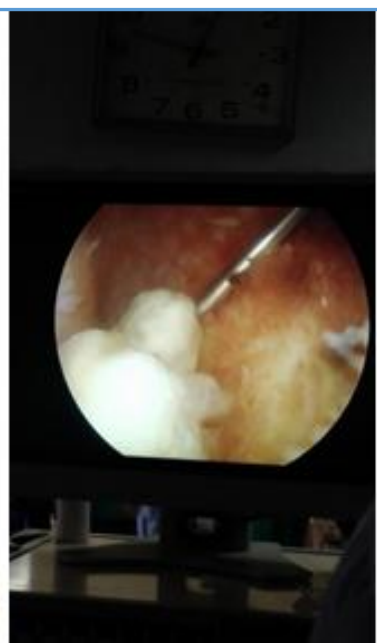

Figure 3

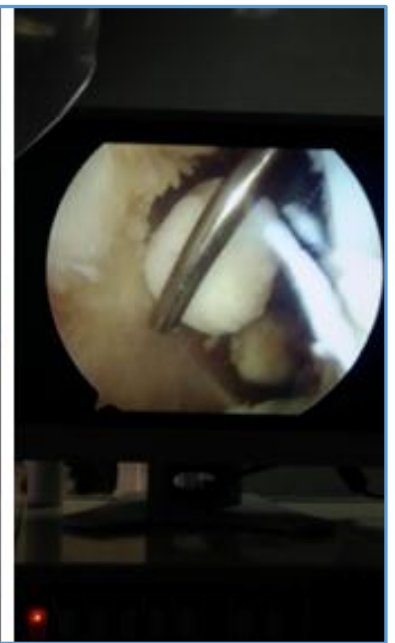

Figure 4

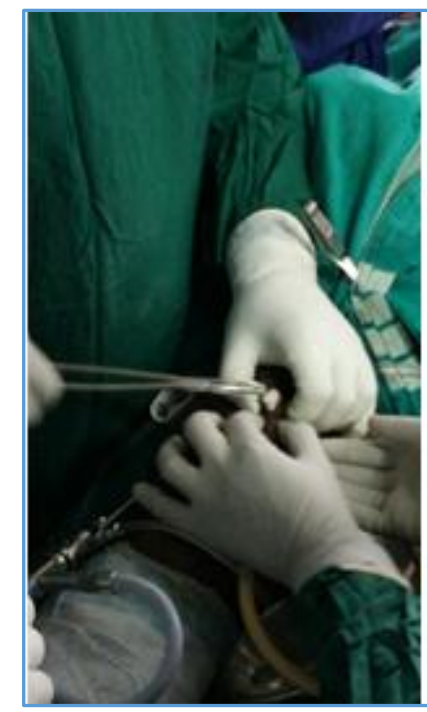

Figure 5

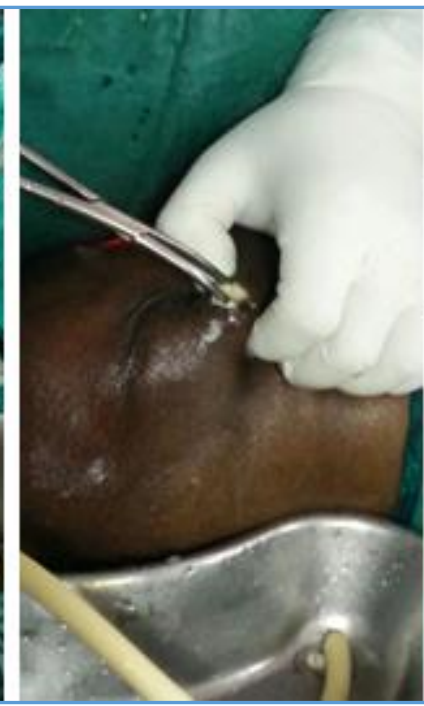

Figure 6

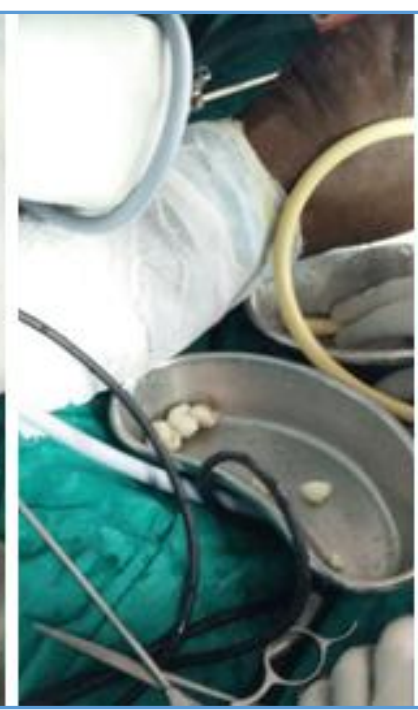

Figure 7

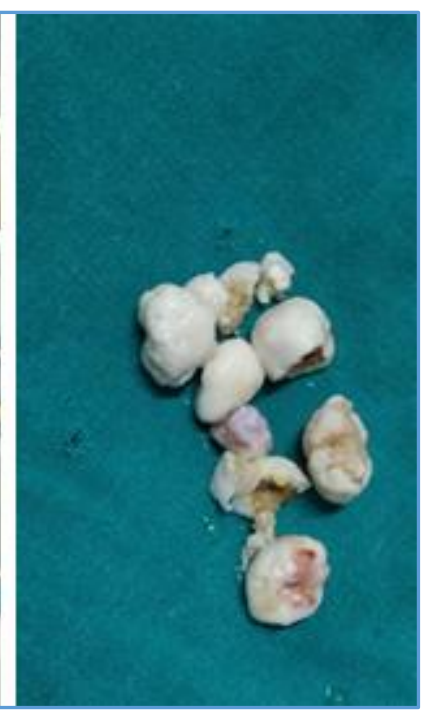

Figure 8

\section{Followup and Evaluation}

Postoperatively patient immobilised with above knee slab, IV antibiotics, analgesics. Static quadriceps exercise and ankle pumping exercise started on day 2. Post-op x-ray taken on day 2 (fig: 1). Suture removal done on $12^{\text {th }}$ POD. After 2 weeks slab was removed and mobilisation started. Knee range of movements checked on $2^{\text {nd }}, 3^{\text {rd }}, 4^{\text {th }}$ weeks. Regular followup was done every month up to first 6 months. At the end of six months, patient's range of motion was Flexion 0$130^{\circ}$ without pain. Patient was able to return to work at the end of 6 months and has pain free acceptable range of movements, right knee, without hindrance of daily activities.

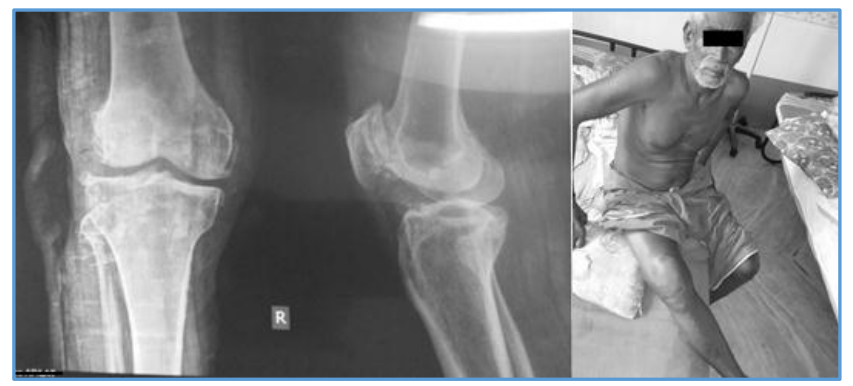

Figure 1

\section{DISCUSSION}

The most striking advantage of removal of loose bodies under arthroscopic control is the reduction in operative trauma and the time required for rehabilitation with obvious benefit for the patient.(9) A second and perhaps more important advantage is the ability to find loose bodies that are not detectable radiologically. The opportunity to examine the joint more comprehensively is possible as a standard arthrotomy makes it possible to examine the joint surface, and identify the source of loose body in most patients. Disadvantages of the procedure included its technical difficulties which demand arthroscopic expertise. The extreme mobility of loose bodies places greater demands upon the surgeon's skill than other arthroscopic repair. Despite some disadvantages, and provided always that the surgeon has sufficient experience of arthroscopy, the removal of loose bodies under arthroscopic control offers considerable benefits.

\section{Technique}

The first stage of the operation is to locate the loose body. A methodical approach to the problem is essential and the common sites of concealment are examined in sequence, including the recess proximal to the medial suprapatellar 
plica, the intercondylar notch, the popliteus tunnel, the recess beneath the posterior horn of the lateral meniscus, the posterolateral compartment and the posteromedial compartment. Loose bodies sink in saline, they tend to fall to the lowest point of the knee which, in supine position, is usually the posteromedial compartment. When the loose body has been identified, it should be immobilised by external finger pressure or transfixation with a percutaneous needle. The final stage of the procedure is to remove the loose body by seizing it squarely across its centre with a grasping instrument such as small Kocher's forceps, artery forceps, or Anderson's tendon tunnelling forceps. The loose bodies are then drawn towards the skin and the capsule incised if the size of the loose body is present, the smallest should be removed first to minimise the leakage of saline from the knee.

\section{CONCLUSION}

Even though the mentioned procedure requires surgical expertise, arthroscopic assisted loose body removal is an accepted novel procedure for synovial chondromatosis with multiple loose bodies.

\section{REFERENCES}

[1] Barnett CH, Davies DV, MacConaill MA. Synovial joints. London: Longmans Green 1961.

[2] Jaffe HL. Tumors and tumorous conditions of the bones and joints. Philadelphia: Lea and Febiger 1959.

[3] Mcivor PR, King DE. Osteochondromatosis of the hip joint. Journal of Bone and Joint Surgery 1962;44-A:87.

[4] Lloyd-Roberts GC. The role of capsular changes in osteoarthritis of the hip joint. Journal of Bone and Joint Surgery Br 1953;35-B(4):627-42.

[5] Milgram JW. The classification of loose bodies in human joints. Clin Orthop 1977;124:282-91.

[6] Jones HT. Loose body formation in synovial osteochondromatosis. Journal of Bone and Joint Surgery 1924;6(2):407-58.

[7] Dandy DJ. Arthroscopic surgery of the knee. Edinburgh and London: Churchill Livingstone 1981.

[8] O'Connor RL. Arthroscopy. Philadelphia and Toronto: JB Lippincott \& Co., 1977.

[9] Murphy FP, Dahlin DC, Sullivan CR. Articular synovial chondromatosis. Journal of Bone and Joint Surgery 1962;44(1):77. 